\title{
ALGEPS
}

REVISTA DE GEOLOGIA, SÈRIE B $n^{\circ} 612$ - Desembre del 2012

ISSN $1132-7014$

D.L.B. 28.178 - 92

10 pàgines

\begin{abstract}
RECORREGUT DE RECERCA GEOLÒGICA I MINERALÒGICA PER LA COMARCA DEL PRIORAT: DES DE BELLMUNT DEL PRIORAT A BELLMUNT DEL PRIORAT (CONCA MINERA DE BELLMUNT DEL PRIORAT)
\end{abstract}

Josep M. Mata-Perelló i Joaquim Sanz Balagué

Aquest recorregut va ésser experimentat amb docents el dia 12b DE MARÇ DEL 2011 


\section{RECORREGUT DE RECERCA GEOLÒGICA I MINERALÒGICA PER LA COMARCA DEL PRIORAT: DES DE BELLMUNT DEL PRIORAT A BELLMUNT DEL PRIORAT (CONCA MINERA DE BELLMUNT DEL PRIORAT) / 12b DE MARÇ DEL 2011}

Per Josep M. MATA-PERELLÓ i Joaquim SANZ i BALAGUÉ

\section{ADVERTIMENTS PREVIS}

Com en altres recorreguts de RECERCA GEOLÒGICA I MINERALÒGICA ..., si es disposa del temps suficient, poden efectuar-se passant per totes les parades i filloles. En cas contrari, recomanem prescindir de les anomenades PARADES - CONDICIONALS.

També cal demanar. abans de començar el recorregut de l'itinerari, quin es l'estat de les pistes i dels camins per on discorrerà, en algun dels seus trams. En aquest itinerari, es transitarà per camins no gaire bons per tal d'anar a diverses mineralitzacions i mines situades a diferents indrets del terme de Bellmunt del Priorat.

Per d'altra banda, recomanem tenir una cura extrema de la NATURA, evitant qualsevol forma d'agressió sobre ella, o de fer-n'hi un mal ús del que en ofereix la nostra mare Terra.

\section{BREU INTRODUCCIÓ}

En aquesta ocasió, el recorregut del present itinerari discorrerà íntegrament, per la Serralada Prelitoral Catalana (integrant del Sistema Mediterrani, una sola de les tres unitats geològiques que constitueixen Catalunya). Així, en aquest itinerari d'origen i fi a Bellmunt del Priorat, sols es transitarà per la Serralada Prelitoral Catalana

Per d'altra banda, aquest itinerari discorrerà per una sola comarca: la del Priorat (i per un sol dels seus municipis, el de Bellmunt del Priorat).

\section{OBJECTIUS FONAMENTALS}

Al llarg del present recorregut, si s'escau, s'intentaran aconseguir el següents objectius fonamentals. 
1.- Estudi i observació dels materials paleozoics (del Carbonífer, fonamentalment). que constitueixen la Serralada Prelitoral Catalana, entre els quals discorrerà la totalitat del recorregut de l'itinerari.

2.- Estudi de diverses mineralitzacions situades entre els materials paleozoics i mesozoics de la Serralada Prelitoral. Entre aquestes, farem esment de les mineralitzacions filonianes de $P b-Z n$..., que trobarem a diversos indrets del terme de Bellmunt del Priorat, encaixades entre els materials del Carbonífer.

3.- Observació d'algunes explotacions subterrànies mineres antigues, com les situades als indrets esmentats dintre de l'apartat anterior, ubicades dintre de la Serralada Prelitoral Catalana.

4.- Observació de les tasques de restauració, si s'escau, efectuades sobre les explotacions anteriors.

5.- Observació dels diferents indrets relacionats amb el Patrimoni Geològic $i$ Miner, que es vagin trobant al llarg del present itinerari. Dintre d'aquest, cal fer esment del relacionat amb el Museu de les Mines de Bellmunt del Priorat, situat a la Mina Eugènia.

6.- Observació de les labors mineres antigues situades la Mina Espinós i a la Mina Blancaderna, dos de les més antigues de Catalunya.

\section{ANTECEDENTS BIBLIOGRÀFICS}

Tot i que hi ha molts antecedents, d'altres itineraris que discorren per indrets coincidents en part amb el que ara presentem (MATA-PERELLÓ, 1996, 1997, 1998a, 1998b, 1998c, 1998d, 1999, 2000a, 2000b, 2001, 2002, 2007, 2008a, 2008b i 2010), no n’hi cap que coincideixi totalment amb el que ara volem presentar, a excepció del darrer.

Pel que fa als antecedents bibliogràfics relatius a les mineralitzacions que veurem al llarg del recorregut, cal fer esment d'un interessant treball; concretament de MELGAREJO i DRAPER (1992), referit a les diferents mineralitzacions de les comarques reusenques.

Un altre antecedent es troba en MATA-PERELLÓ (1991), referit a les mineralitzacions del conjunt dels Països Catalans. Tanmateix, també farem esment de CANALS (1985).

Pel que fa als trets de la geologia d'aquestes comarques, ens referirem de nou al treball de MELGAREJO i DRAPER (1992); així com a les publicacions de l'IGME (1974, 1978a, 1978b i 1978c). Per d'altra banda, també farem esment de dos treballs referits al conjunt dels Països Catalans. Es tracta dels de: GUIMERÀ et altri (1992) i de RIBA et altri (1979).

Tots aquests treballs esmentats, i d'altres, figuraran per ordre alfabètic a l'apartat dedicat a les REFERÈNCIES BIBLIOGRÀFIQUES. 


\section{DESCRIPCIÓ DEL RECORREGUT DE L'ITINERARI}

El recorregut del present itinerari començarà i finalitzarà al municipi de Bellmunt del Priorat. En aquest recorregut es visitaran diverses instal-lacions i labors mineres, com les corresponents a la Mina Eugènia, Mina Regia I, Mina Regia II, la Cresta, a la Mina Blancaderna i a la Mina Espinós. Tanmateix es visitarà la Mina Renàlia, si s'escau i de retirada.

\section{DESCRIPCIÓ DE L'ITINERARI}

Com de costum, estructurarem el recorregut de l'itinerari en una sèrie de PARADES, que tot seguit anirem veient. En cada una d'aquestes aturades farem un breu comentari (geològic o mineralògic, segons s'escaigue).

En cada cas indicarem, entre parèntesi el full topogràfic del "Mapa Topogràfico Nacional" a escala 1:50.000 on es troba l'aturada, que en aquest cas serà sempre algun dels següents dos fulls: 471 (dit també de Mora) i 472 (dita de Reus). Aquests fulls han estat publicats per l’Instituto Geografico y Catastral de España. següent:

Així doncs, la relació ordenada de les aturades que composen aquest itinerari, és la

PARADA 1. INSTAL·LACIONS DE LA MINA EUGÈNIA, MUSEU DE LA MINERIA DE BELLMUNT DEL PRIORAT, (terme municipal de Bellmunt del Priorat, comarca del Priorat). (Full 471).

L'itinerari començarà al mateix poble de Bellmunt del Priorat, i més concretament a la Casa de les Mines. A poca distància de Bellmunt (a uns 0’2 Km) es troben les antigues instal-lacions de la Mina Eugènia. En aquest indret, cal fer la primera aturada, després de recórrer $1 \mathrm{Km}$ i escaig, des del poble.

El recorregut l'haurem començat a la Casa de les Mines, recentment restaurada. I més avall és on es troba el Museu. Pel que fa aquest, aquestes instal-lacions mineres consisteixen en una planta de tractament del mineral (actualment en fase de recuperació), i en un pou amb dos nivells practicables, als quals s'hi arriba mitjançant unes escales. Actualment aquesta mina constitueix la seu d el Museu de la Mineria de Bellmunt del Priorat, i no és pot entrar a la mina sense permís del mateix.

També cal fer esment de que al passar pel poble de Bellmunt del Priorat (just a la sortida del mateix), haurem tingut ocasió de veure l'àntic Poblat Miner (per on pasarem després, en retornar de les altres mines.

Pel que fa a la mineralització explotada a la Mina Eugènia, cal dir que consisteix en una sèrie de filonets de GALENA-ESFALERITA, encaixats entre pòrfirs granítics. Els filonets formen una complexa trama que omple els diàclasis del pòrfir. 


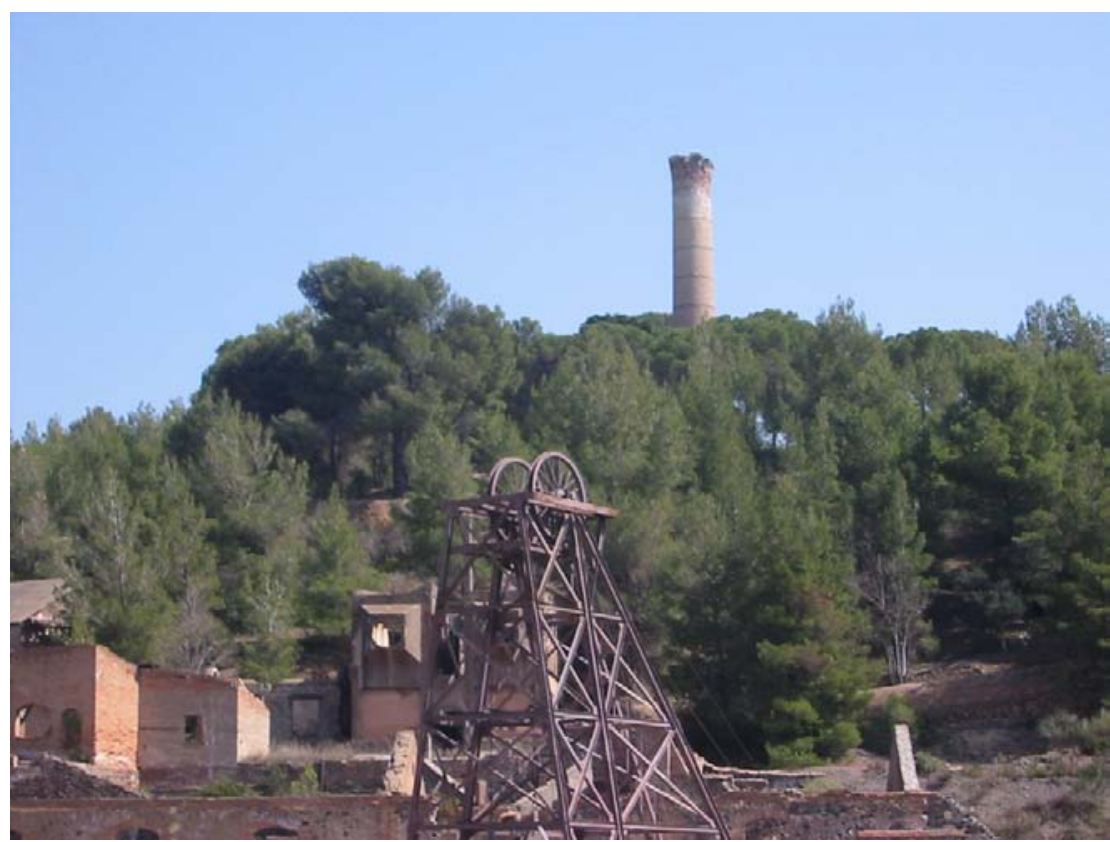

FOTOGRAFIA 1. El Castellet de la Mina Renàlia, al Museu Miner de la Mina Eugènia

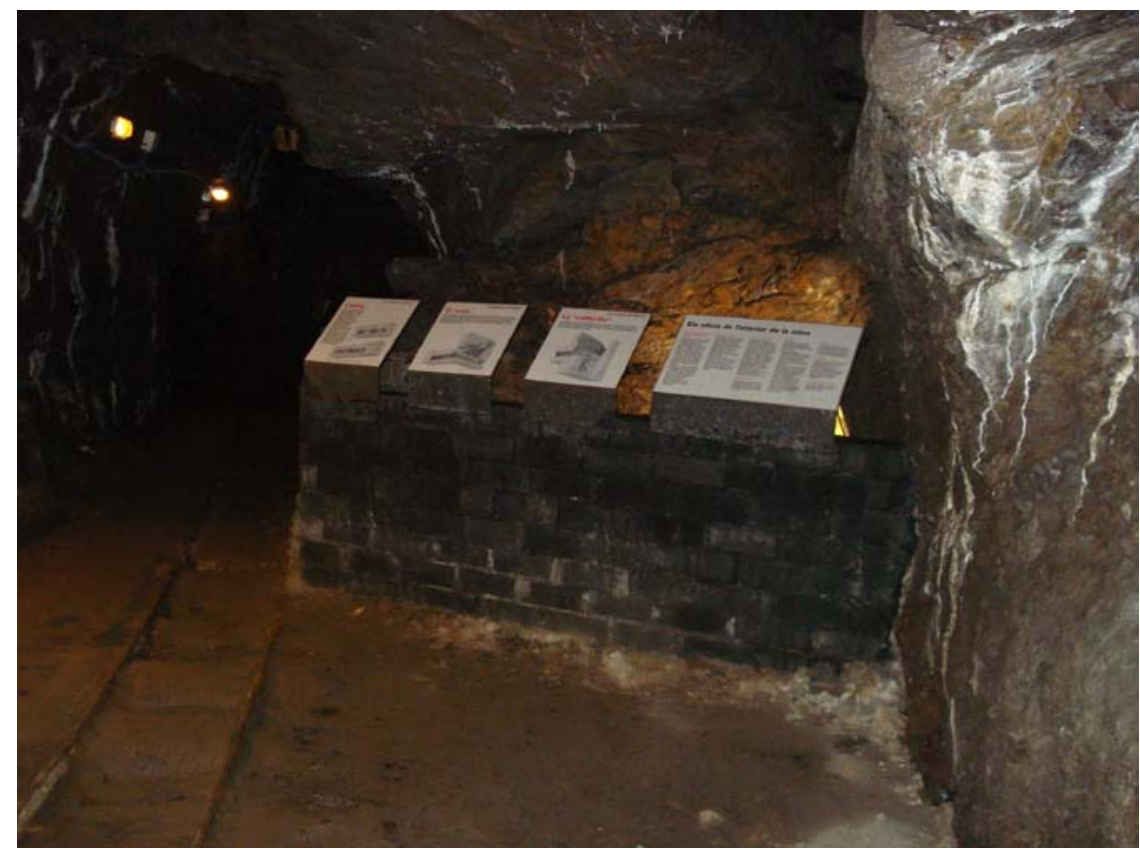

FOTOGRAFIA 2. Un aspecte de l'interior del Museu

Entre els sulfurs primaris presents al jaciment, cal fer esment dels següents minerals: CALCOPIRITA, ESFALERITA, GALENA, MARCASSITA i PIRITA; I entre els minerals d'alteració, es troben: ATZURITA, CERUSSITA, HIDROCINCITA, limonita. i MALAQUITA.

També cal fer esment d'altres minerals, com els següents: ANQUERITA, BARITINA, CALCITA, DOLOMITA, MOSCOVITA, QUARS i SIDERITA. Igualment, cal fer esment de la presència de dendrites de PIROLUSITA. 
PARADA 2. INSTAL-LACIONS DE LA MINA REGIA I, i DE LA MINA REGIA II (O REGIA ANTIGA), (terme municipal de Bellmunt del Priorat, comarca del Priorat). (Full 471).

Des de la parada anterior, cal seguir cap al Molar, fins arribar a les instal-lacions de l'antiga Mina Regia, situades a la dreta del camí. En aquest indret, caldrà fer la present aturada, després d’haver recorregut 2-2’5 Km, més.

En ambdós mines hi ha mineralitzacions filonianes, fonamentalment de $\mathrm{Pb}-\mathrm{Zn}$, encaixades entre els pòrfirs granítics que tallen als materials carbonífers. Aquestes mineralitzacions es relaciones amb una important fractura, de direcció ENE-WSW. Així, sovint la mineralització te aspecte bretxoide.

Entre els minerals presents, cal fer esment dels següents: CALCOPIRITA, ESFALERITA, GALENA, MARCASSITA i PIRITA. Entre els minerals d'alteració es troben: GOETHITA (terrosa i limonítica), ATZURITA, CERUSSITA, HIDROCINCITA, MALAQUITA i ANGLESITA.

També es troben presents molts carbonats, que cementen les bretxes, com: ANQUERITA, CALCITA, DOLOMITA i SIDERITA. Altres minerals presents són la BARITINA i el QUARS.

De tots ells, possiblement els més abundants són els de plom, (i en especial la galena); així com l'anquerita i la siderita, entre els carbonats. Tots ells es poden trobar fàcilment a les escombreres de la Mina Regia II.

Des d'aquest indret es pot observar clarament la discordança entre els materials triàsics del Serrat de la Roca (al Nord de la mina), i els materials paleozoics i granítics. Per d'altra banda, cap el NE es poden veure els nivells terciaris detrítics de la Serra del Montsant, amb la formació del mateix nom.

\section{PARADA 3. MINA BLANCADERNA, (terme municipal de Bellmunt del Priorat, comarca del Priorat). (Full 471).}

Des de la parada anterior, cal seguir pel camí que condueix cap a Bellmunt del Priorat. Una mica més amunt, es trobarà un trencall que porta cap a les antigues explotacions de la Mina Blancaderna, per on farem una nova aturada, a uns 0'5 Km de l'anterior. Tot i així, podíem baixar directament per la muntanya, en uns 200m, tot i així és força perillós per la gran quantitat de pous miners antics.

En aquest recorregut, hem tornat a trobar els materials paleozoics ja esmentats anteriorment: els materials del Carbonífer tallats per gran quantitat de dics porfídics que els travessen.

En aquest indret hi havia una antiga explotació (possiblement romana i reactivada durant els segles XVI i XVII, però molt dèficit de reconèixer per la mineria posterior dels segles XIX i XX). Tot i així es conserven algunes galeries i pous antics. Com a les mines anterior, el principal mineral explotat va ésser la GALENA, sovint argentífera. 


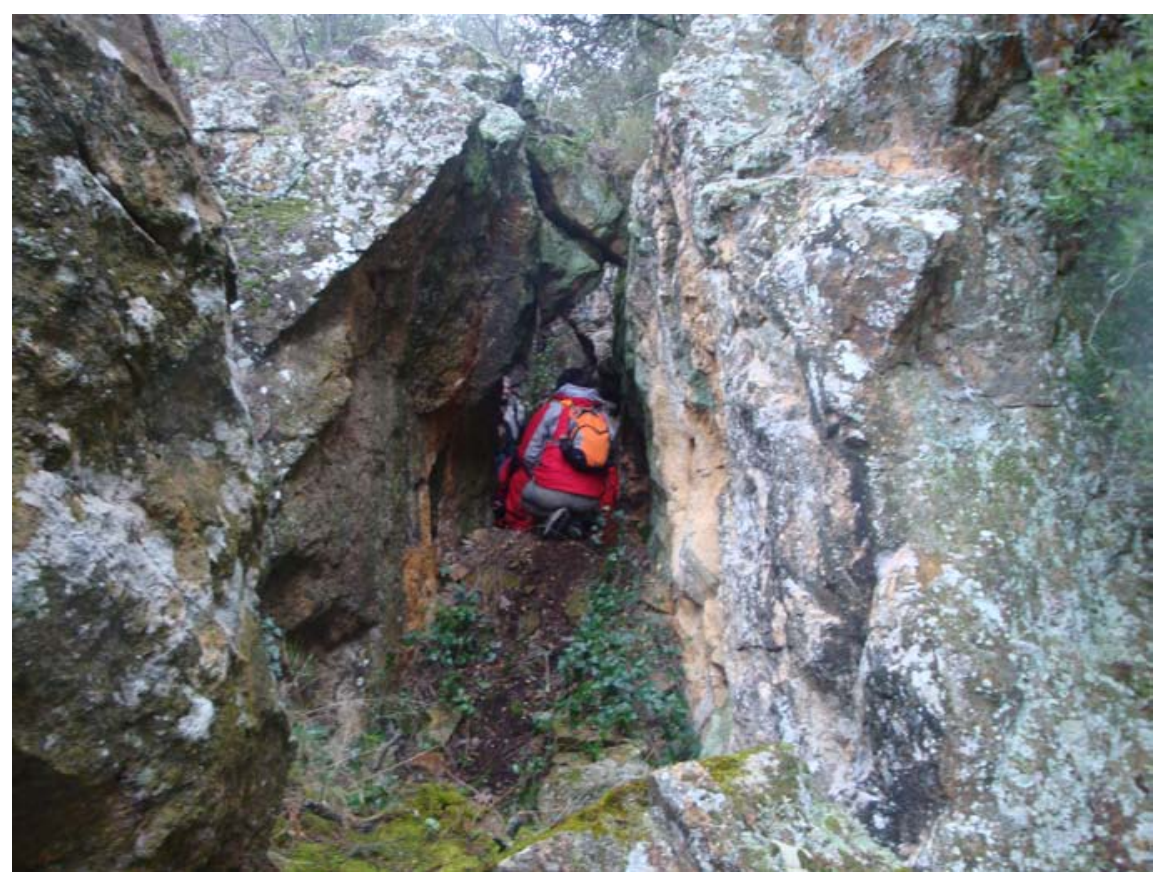

FOTOGRAFIA 3. Mina Blancaderna

PARADA 4. MINA DEL BARRANC ESPINOS, (terme municipal de Bellmunt del Priorat, comarca del Priorat). (Full 471).

Des de la parada anterior, cal tornar endarrere, per tal de recuperar el camí que condueix per dalt de la carena cap a Bellmunt del Priorat, tot venint des de la Mina Regia. Per aquest camí passarem enfront d'on hi ha la Cresta. Després passarem pels voltants d'un antic pou (on podríem parar).

I finalment, arribarem a un collet, d'on surt un caminet que baixa cap a les antigues explotacions de la Mina del Barranc Espinós, on farem una nova aturada, a $1 \mathrm{Km}$ de l'anteriorment feta.

En aquest recorregut, hem trobat afloraments dels materials paleozoics esmentats a les parades i recorreguts anteriors. Aquests materials són també els que afloren a l'indret on ara ens trobem. En aquest lloc hi havia unes antigues explotacions mineres, i reactivades posteriorment durant els segles XVII i XVII. En aquestes explotacions es treia GALENA, molt sovint argentífera.

$\mathrm{Al}$ respecte d'aquestes explotacions, cal tenir molta cura, ja que hi ha molts pous i pouets per arreu, molt perillosos i tapats per la vegetació

PARADA 5. LA CRESTA, (terme municipal de Bellmunt del Priorat, comarca del Priorat). (Full 471).

Des de la parada anterior, cal continuar cap a Bellmunt, pel camí que que procedeix la Mina Regia, anant per la carena. Més endavant es trobarà un trencall cap a la dreta. I poc després un altre cap a l'esquerra. Cal agafar aquest i continuar a peu. Així s'arribarà a 
l'indret on hi ha la mina, i on farem una nova parada, a uns $1^{\prime} 5-2 \mathrm{Km}$ de la prada anterior.

En aquest recorregut. hem anat circulant per la carena de la muntanya que rodeja Bellmunt pel NW. I ho hem fet entre afloraments dels materials paleozoics, fonamentalment del Carbonífer.

En arribar a l'indret de la parada, ens trobarem amb un impressionant dic de pòrfir, que travessa els materials paleozoics. I en relació amb aquesta intrusió hi ha un filonet explotat superficialment. Cap a la part baixa de la muntanya, aquest filonet ha estat explotat per mineria subterrània.

Entre els minerals presents (molt sovint visibles en superfície) hi ha la GALENA i en menys grau l'ESFALERITA. També es veuen altres minerals com la PIRITA, GOETHITA (limonítica); així com indicis de CERUSSITA i ANGLESITA.

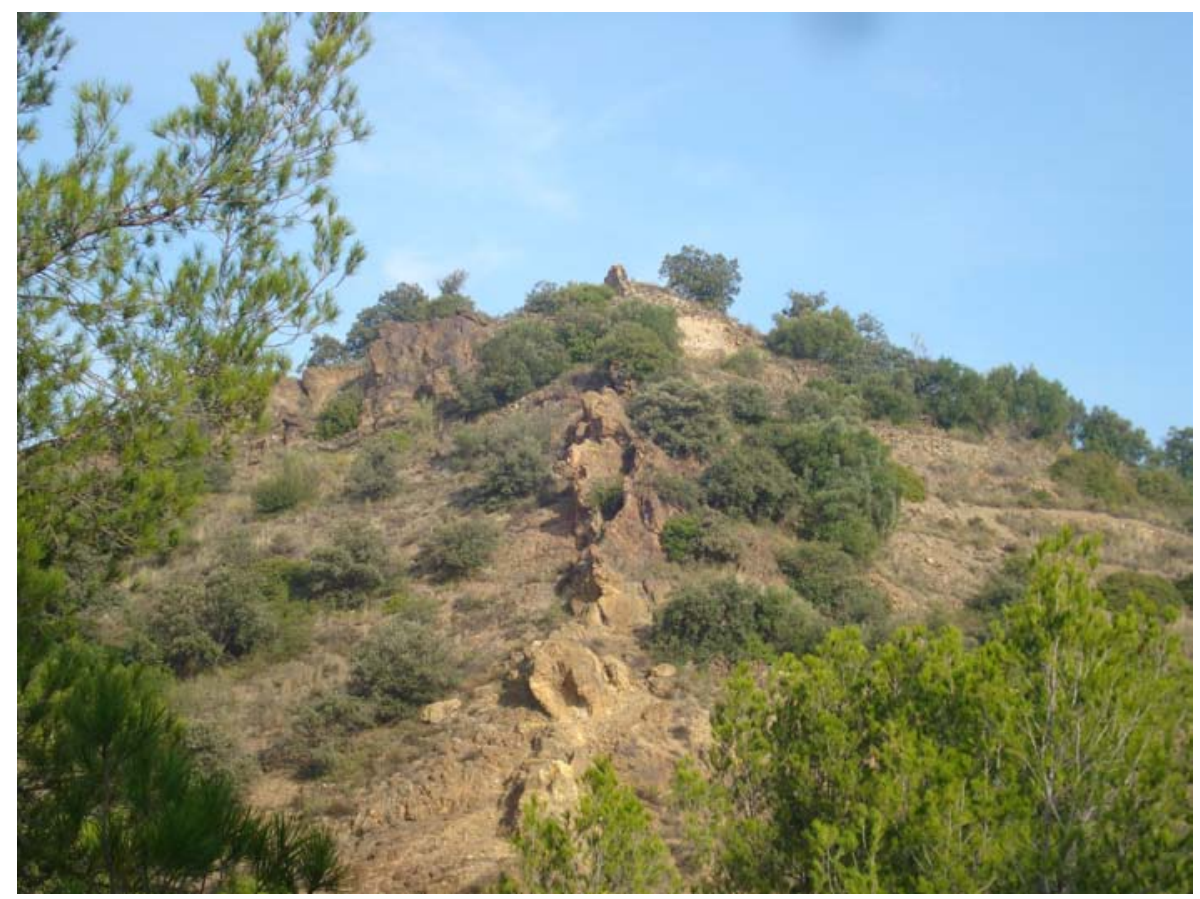

FOTOGRAFIA 4. La Cresta, des del camí a la Mina Regia

PARADA 6. BARRI MINER DE BELMUNT DEL PRIORAT, (terme municipal de Bellmunt del Priorat, comarca del Priorat). (Full 471).

Després de realitzar la parada anterior, cal continuar cap a Bellmunt del Priorat, i més concretament cap a la Casa de les Mines. Després es pujarà cap al poble, circulant pel Barri de les Mines. En aquest indret es farà una nova aturada, a uns 1'5 Km de la parada anteriorment realitzada.

El barri es troba en una posició oriental en relació al poble de Bellmunt y està format per uns pocs carrers adossats al poble vell. Es tracta de un barri construït a principis 
i mitjans del segle passat on vivien els miners. Aquest barri, es troba molt ben conservat i hi viu bastants habitants..

Es un dels millors exemples de colònia minera, en la que s'ha mantingut la població, malgrat tancar-se les mines fa més de quaranta anys.

\section{AQUÍ FINALITZA EL RECORREGUT DE L'ITINERARI}

\section{BIBLIOGRAFIA}

GUIMERÀ, J. et altri (1992).- Geologia (II), Història Natural dels Països Catalans, Vol. 2, 547 pag. Enciclopèdia catalana, S.A., Barcelona

IGME (1974a).- Mapa Geològico de España, a escala 1:50.000 (Segunda Série). Full i memòria $\mathrm{n}^{\circ} \underline{471}$ (Mora d’Ebro). Ins. Tecnológico y GeoMinero de España. Minist. Indus. Energia. Madrid

IGME (1974b).- Mapa Geológico de España a Escala 1:50.000 (2a Sèrie). Full i Memòria $n^{0} \underline{472}$ (Reus). Inst. Tecnológico y GeoMinero de España. Minist. Indus. Ener. Madrid

MATA-PERELLÓ, J.M. (1991).- Els Minerals de Catalunya Arxius de la Secció de Ciències, Vol XCIII, 444 pag. Institut d’Estudis Catalans, Barcelona

MATA-PERELLÓ, J.M. (1996).- Itinerari geològic i mineralògic pel Baix Camp i pel Priorat: des de l'Aleixar a Cornudella, Porrera i al Molar. Inèdit. 6 pàg. Manresa

MATA-PERELLÓ, J.M. (1997).- Recerca geològica i mineralògica per la comarca del Priorat: des de Cornudella a la Venta del Pobill, a Porrera i al Molar. Inèdit. 8 pàgines. Manresa

MATA-PERELLÓ, J.M. (1998a).- Recerca geològica i mineralògica per les comarques del Baix Camp i del Priorat: des de les Borges del cap al Molar. Inèdit, 14 pàgines. Manresa

MATA-PERELLÓ, J.M. (1998b).- Recorregut de recerca geològico-mineralògica i geoambiental per les comarques del Baix Camp i del Priorat: des de les Borges del cap al Molar per Pradell de la Teixeta. Inèdit, 18 pàgines. Manresa.

MATA-PERELLÓ, J.M. (1998c).- Recorregut de recerca geològica i mineralògica per les comarques del Baix Camp i del Priorat: des de l'Aleixar al Mas del Mestre, i des del Coll de la Teixeta al Coll de Falset i al Molar. Algeps, sèrie $B, \mathrm{n}^{\circ} 125,16$ pàgines. Manresa

MATA-PERELLÓ, J.M. (1999).- Recerca geològica i mineralògica per les comarques del Baix Camp i del Priorat: des de les Borges del Camp a Pradell de la Teixeta i al Molar. Algeps, sèrie $B, \mathrm{n}^{\circ} 125,16$ pàgines. Manresa 
MATA-PERELLÓ, J.M. (2000a).- Recorregut de recerca geològica i mineralògica per les comarques del Baix Camp, de la Ribera d'Ebre i del Priorat: des de Reus a Mont-roig del Camp, a Tivissa i a Falset. Xaragall, sèrie B, nº 129, 12 pàgines. Manresa

MATA-PERELLÓ, J.M. (2000b).- Recorregut de recerca geològica i mineralògica per les comarques del Baix Camp i del Priorat: des de Reus a Escornalbou i l'Argentera, i del Coll de la Teixeta al Coll de Falset i al Molar. Xaragall, sèrie B, $\mathrm{n}^{\circ}$ 133, 18 pàgines. Manresa

MATA-PERELLÓ, J.M. (2001).- Recorregut de recerca geològica i mineralògica per les comarques del Baix Camp i del Priorat: des del Coll de la Teixeta al Coll de Falset a Bellmunt del Priorat i al Molar. Algeps, sèrie B, $n^{0}$ 194, 15 pàgines. Manresa

MATA-PERELLÓ, J.M. (2002).- Recorregut de recerca geològica i mineralògica a través del patrimoni miner de la comarca del Priorat: des de Bellmunt del Priorat al Molar. Inedit, 10 pàgines. Manresa

MATA - PERELLÓ, J.M. (2004).- Recorregut de recerca geològica i mineralògica per la comarca del Priorat, a través del seu patrimoni miner: des de Pradell de la Teixeta a Falset i al Molar. Inèdit. 13 pag. Manresa

MATA - PERELLÓ, J.M. (2007).- Recorregut de recerca geològica i mineralògica per les comarques del Baix Camp i del Priorat: des de les Borges del Camp cap a Riudecanyes, l'Argentera, Duesaigües, al Coll de la Teixeta i a Bellmunt del Priorat. Inèdit. 12 pàgines. Manresa

MATA - PERELLÓ, J.M. (2008a).- Recorregut de recerca geològica i mineralògica a través de la comarca del Priorat: des de Marçà cap a Bellmunt del Priorat, el Molar i cap a la Figuera de Falset. Inèdit. 12 pàgines. Manresa

MATA - PERELLÓ, J.M. (2008b).- Apunts per a un recorregut de recerca geològica i mineralògica per la comarca del Priorat: des de Bellmunt del Priorat a Bellmunt del Priorat (mines Blancaderna, Espinós, la Cresta i Lagarto). Inèdit. 8 pag. Manresa

MATA - PERELLÓ, J.M. (2010).- Recorregut de recerca geològica i mineralògica per la comarca del Priorat: des de Bellmunt del Priorat a Bellmunt del Priorat (Mines: Eugènia, Blancaderna, Espinós, la Creta i Renàlia). 10 pàgines. Manresa

MATA-PERELLÓ, J.M. i COLLDEFORNS, B. (1994). Selecció d’itineraris geològics i mineralògics per les comarques del Baix Camp, Conca de Barberà, Priorat i Ribera d’Ebre. Xaragall, nº 28, 36 pàgines. Manresa

MELGAREJO I DRAPER J.C. (1992).- Estudio geológico y metalogenético del paleozoico del sur de las Cordilleras Costeras Catalanas. Memórias del Instituto Tecnológico y Geo-Minero de España , tomo 103, 605 páginas. Madrid

RIBA ARDERIU, O. Et altri. (1976).- Geografia física dels Països Catalans. Edit Ketres, 205 pàgines. Barcelona 